\title{
Treatment of distal clavicle fractures using a Scorpion plate and influence of timing on surgical outcomes: a retrospective cohort study of 105 cases
}

Ryogo Furuhata ${ }^{1 *}$, Masaaki Takahashi ${ }^{1}$, Teppei Hayashi ${ }^{1}$, Miyu Inagawa', Aki Kono ${ }^{1}$, Noboru Matsumura², Yusaku Kamata', Hiroshi Arino ${ }^{1}$ and Hideo Morioka ${ }^{1}$

\begin{abstract}
Background: Plate fixation is an established method for treating unstable distal clavicle fractures. However, the appropriate timing of surgery for acute distal clavicle fractures remains unclear. The present study aimed to evaluate the clinical outcomes of osteosynthesis using a Scorpion plate and to assess the influence of surgery timing on the surgical outcomes for acute unstable distal clavicle fractures.

Methods: We retrospectively reviewed 105 patients who underwent fixation for acute unstable distal clavicle fractures (Neer type II and V) using the Scorpion plate between 2008 and 2018. Patients were divided into early (45 patients) and delayed (60 patients) treatment groups based on the timing of the surgical intervention (within or after 7 days). The outcomes were postoperative complications (nonunion, peri-implant fracture, plate loosening, plate-related pain, and stiffness). We evaluated the outcomes from X-ray radiographs and clinical notes.

Results: Among the 105 patients, nonunion, plate loosening, plate-related pain, and stiffness were observed in six patients $(5.7 \%)$, four patients (3.8\%), seven patients (6.7\%), and one patient (1.0\%), respectively. The nonunion rate was significantly higher in the delayed treatment group than that in the early treatment group $(P=0.036)$. Although the difference was not significant, plate loosening and stiffness were only observed in the delayed treatment group.

Conclusion: Our results demonstrated that osteosynthesis using Scorpion plates achieved satisfactory surgical outcomes for unstable distal clavicle fractures. In addition, this study suggested that performing surgery within 6 days after injury is recommended to reduce postoperative complications.
\end{abstract}

Keywords: Distal clavicle fracture, Plate, Scorpion plate, Outcome, Complication, Union, Timing of surgery

\section{Introduction}

Distal clavicle fractures have a high nonunion risk (22$50 \%)$ in patients treated non-surgically due to the instability caused by the two opposing forces of trapezius traction and the weight of the upper extremity [1-3].

\footnotetext{
*Correspondence: ryogo4kenbisha@gmail.com

${ }^{1}$ Department of Orthopaedic Surgery, National Hospital Organization Tokyo Medical Center, 2-5-1, Higashigaoka, Meguro-ku, Tokyo 152-8902, Japan Full list of author information is available at the end of the article
}

Therefore, for unstable distal clavicle fractures classified as Neer type II or V [4,5], surgical treatment is usually indicated [6]. To date, we have used the anatomical nonlocking plates, "SCORPION" (Fig. 1a and b) and "SCORPION ${ }^{\circ}$ NEO" (Fig. 2a and b) (Aimedic MMT, Tokyo, Japan), to treat unstable distal clavicle fractures. In fixation with Scorpion plate, the distal bone fragment is grasped by the plate arm and fixed with one or two screws, while the proximal bone fragment is fixed with

(C) The Author(s). 2020 Open Access This article is licensed under a Creative Commons Attribution 4.0 International License, which permits use, sharing, adaptation, distribution and reproduction in any medium or format, as long as you give appropriate credit to the original author(s) and the source, provide a link to the Creative Commons licence, and indicate if changes were made. The images or other third party material in this article are included in the article's Creative Commons licence, unless indicated otherwise in a credit line to the material. If material is not included in the article's Creative Commons licence and your intended use is not permitted by statutory regulation or exceeds the permitted use, you will need to obtain permission directly from the copyright holder. To view a copy of this licence, visit http://creativecommons.org/licenses/by/4.0/ The Creative Commons Public Domain Dedication waiver (http://creativecommons.org/publicdomain/zero/1.0/) applies to the data made available in this article, unless otherwise stated in a credit line to the data. 


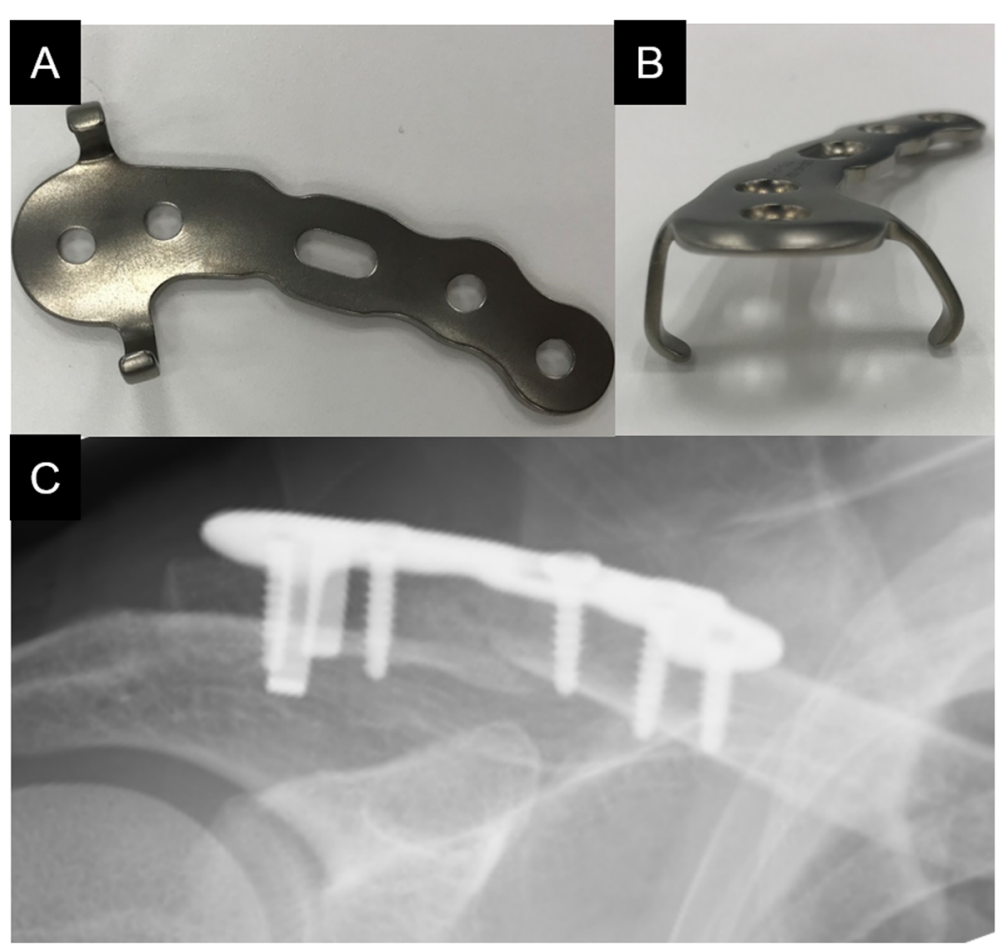

Fig. 1 The photo images demonstrate a SCORPION ${ }^{\circledR}$ plate (a and $\mathbf{b}$ ). Plain radiograph showing osteosynthesis using a SCORPION ${ }^{\circledR}$ plate within six days after injury (c)

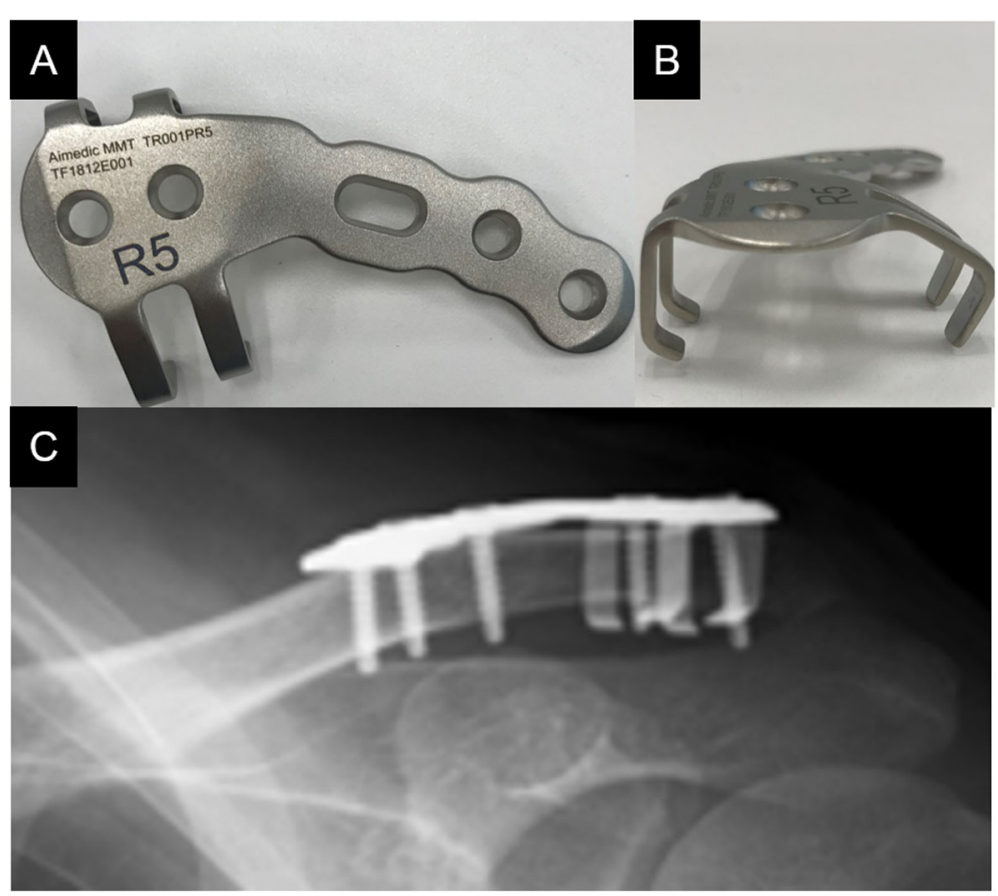

Fig. 2 The photo images demonstrate a SCORPION` NEO plate (a and b). Plain radiograph showing osteosynthesis using a SCORPION® NEO plate within six days after injury (c) 
three screws. The bending stiffness and torsional stiffness of the Scorpion plate were reported to be significantly higher than those of tension band wiring and were equivalent to those of hook plates [7]. However, there have been no large clinical studies on the clinical results of osteosynthesis using Scorpion plates.

Plate fixation for distal clavicular fractures has been reported to achieve satisfactory bone union rates [8-14]; however, one of the important clinical problems is the rate of postoperative complications. While hook plates showed good outcomes for fractures with comminuted distal bone fragments, various complications, such as peri-implant fracture, dislocation, and limited range of motion were reported $[6,10,15]$. On the other hand, plates that are fixed proximal to the acromioclavicular joint have been reported as leading to fewer complications than the hook plate, since the plates do not disturb the acromioclavicular joint motion [14, 16, 17]. However, complications such as plate fracture due to trauma, nonunion, and plate loosening can occur, albeit at a lower frequency, and some cases require re-operation $[18,19]$. Nevertheless, risk factors for these postoperative complications remain largely unknown. The incidence of postoperative complications is reported to be high in patients for whom more than 4 weeks had elapsed since the injury $[16,20]$. These reports suggest that the time to surgery may affect the occurrence of postoperative complications. However, the appropriate timing of surgery for acute distal clavicle fractures is still unclear. We hypothesized that delayed surgical intervention would make the anatomical reduction difficult and lead to higher complications than early intervention.

The purpose of this study was to evaluate the clinical outcomes of distal clavicle fractures using the Scorpion plate and to assess the appropriate timing of surgery for acute unstable distal clavicle fractures.

\section{Methods}

\section{Patient selection}

This was a retrospective study of patients who underwent osteosynthesis using Scorpion plates for unstable distal clavicle fractures (Neer type II or V) between 2008 and 2018. During this period, SCORPION ${ }^{\circ}$ plates were used from April 2008 to March 2014, and SCORPION ${ }^{\circ}$ NEO plates were used from April 2014 to March 2018. The surgical techniques for these two plates are generally the same, with the exception of the presence of one plate arm in SCORPION ${ }^{\circ}$ plates grasping the distal fragment compared with the two plate arms in SCORPION ${ }^{\circ}$ NEO plates. The procedures were performed at a single general hospital by 14 surgeons (all trainees who were not specialized in shoulder surgery). We included patients with acute clavicle fractures within 3 weeks of injury. We excluded patients with inadequate follow-up, which was defined as the inability to continue follow-up until radiographically confirmed fracture union was observed or the cases in which the follow-up of patients was not feasible for at least 6 months after surgery.

We identified 110 patients who met the inclusion criteria. Five patients were excluded due to inadequate follow-up. The mean ( \pm standard deviation) age of patients at the time of surgery was $47.0 \pm 16.7$ years (range: 14-89 years). The affected side was the right for 58 patients and the left for 47 patients. There were 55 smokers (52.3\%). The type of clavicle fracture was Neer classification type IIA in 23 patients (22.0\%), type IIB in 63 patients (60.0\%), and type $\mathrm{V}$ in 19 patients $(18.1 \%)[4,5]$. The type of plates used was SCORPION ${ }^{\circ}$ plate $(60$ patients, accounting for $57.1 \%$ ) and SCORPION NEO ${ }^{\circ}$ plate (45 patients, accounting for $42.9 \%$ ). Patients who met these criteria were further divided into two groups; an early treatment group (early group), which included patients for whom the time from injury to surgery was within 6 days, and a delayed treatment group (delayed group), which included patients for whom time to surgery was 7 days or more. This cut-off was set based on a previous report on acute proximal humeral fracture for which delayed surgical intervention (six or more days after the injury) was related to a significant increase in postoperative complications [21] because there was no reference describing the timing of surgery for acute distal clavicular fractures. The early group included 45 patients and the delayed group included 60 patients (Table 1).

\section{Surgical procedure}

All patients underwent fracture fixation in a beach chair position under general anesthesia. The approach was from the superior side of the clavicle, and the acromioclavicular joint capsule was preserved. After temporarily fixing distal bone fragments with $2.0 \mathrm{~mm}$ Kirschner wires under fluoroscopy, if any third bone fragments were present, we sutured these fragments to the clavicle using high-strength absorption sutures. We ultimately fixed these fracture fragments using a SCORPION ${ }^{\circ}$ plate (Fig. 1c) or a SCORPION ${ }^{\circ}$ NEO plate (Fig. 2c). Two distal and three proximal cortical screws were inserted to fix the plates. These plates are characterized by one plate arm attached to SCORPION ${ }^{\circ}$ plates and two plate arms in $\mathrm{SCORPION} \mathrm{NEO}^{\circ}$ plates. In addition, these plate arms are bent with a specialized instrument to pressurefix the distal fragment (Figs. 3 and 4). If the fixation was considered to be insufficient, fixation with $2.0 \mathrm{~mm}$ Kirschner wire, or coracoclavicular ligament reconstruction with a suture-anchor, was additionally performed. After surgery, the affected arm was kept in a sling for 13 weeks depending on the postsurgical fixation strength. Pendulum exercises were started the day after surgery and passive and active range of motion exercises were 
Table 1 Patient demographics

\begin{tabular}{llll}
\hline & Early group $(n=45)$ & Delayed group $(n=60)$ & $P$ value \\
\hline Time from injury to surgery (days) & $3.9 \pm 1.5$ & $10.7 \pm 3.4$ & $<0.001{ }^{*}$ \\
Age (years) & $44.4 \pm 14.9$ & $49.0 \pm 17.6$ & 0.194 \\
Male/Female & $35 / 10$ & $50 / 10$ & 0.473 \\
Side of Injury, Right/Left & $27 / 18$ & $31 / 29$ & 0.395 \\
Smoker/Non-smoker & $26 / 19$ & $29 / 31$ & 0.338 \\
Neer Type lla & 7 & 33 & 0.173 \\
Neer Type Ilb & 30 & 11 & 0.227 \\
Neer Type V & 8 & $37 / 23$ & 0.942 \\
Type of plate, & $23 / 22$ & & 0.279 \\
SCORPION $/$ SCORPION NEO & & 13 & 0.430 \\
Additional fixation with Kirschner wire or suture anchor & 7 & & \\
\hline * P<0.05 & & &
\end{tabular}

${ }^{*} P<0.05$

permitted after 1 week. Implant removal was performed when bone union was obtained at least 6 months after the operation and in the case that the patient requested the removal.

\section{Outcomes}

The outcomes were the occurrence of complications (nonunion, peri-implant fracture, plate loosening, plate-related pain, and stiffness requiring arthroscopic capsulotomy)

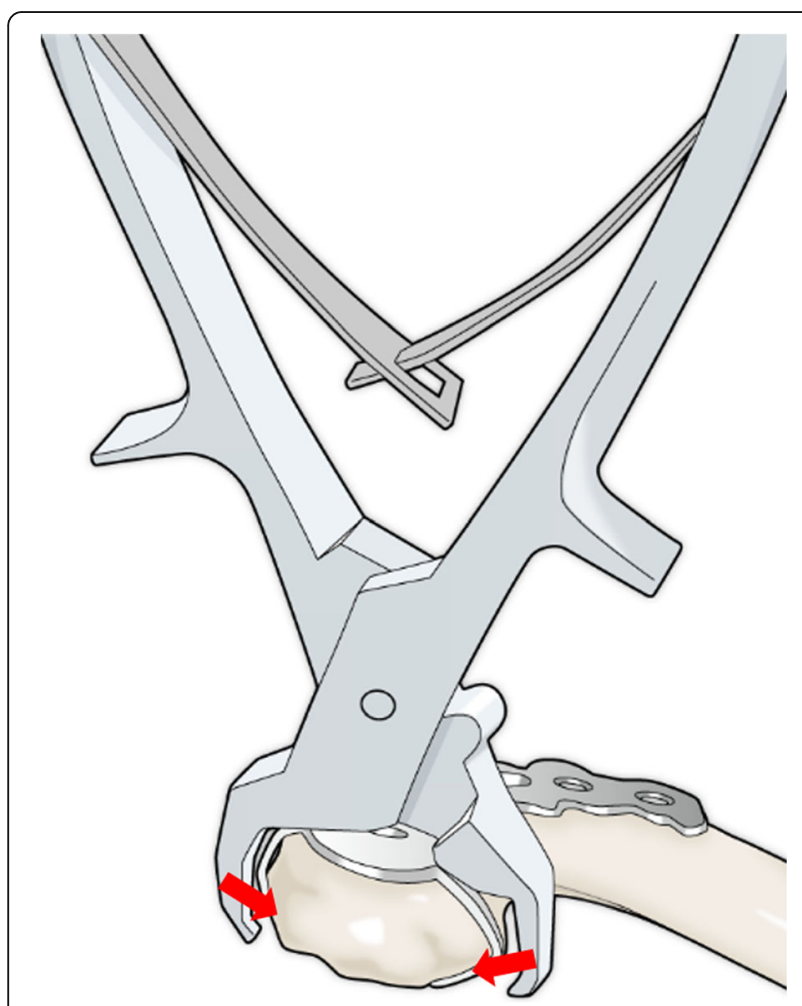

Fig. 3 A schematic image showing that the plate arm was bent using a specialized instrument so that it firmly grasped the clavicle and postoperative fracture gap. A single examiner, who did not participate in any surgeries, blindly evaluated the plain radiograph images; thereafter, evaluation of the clinical outcomes and assignment of the early and delayed groups were performed by clinical notes to reduce the bias of measurements. According to a previous report [22], nonunion was defined as a lack of bone bridging after more than 12 months after injury. We defined plate loosening as any screws backing out or a plate displacement greater than $3 \mathrm{~mm}$ above the clavicle. Pain from the plate fixation was evaluated based on patient complaints 6 months after surgery (prior to implant removal). We compared the incidence of postoperative complications between the early group and delayed group.

To further evaluate whether there were any differences in outcomes between the $\mathrm{SCORPION}^{\circ}$ plates and

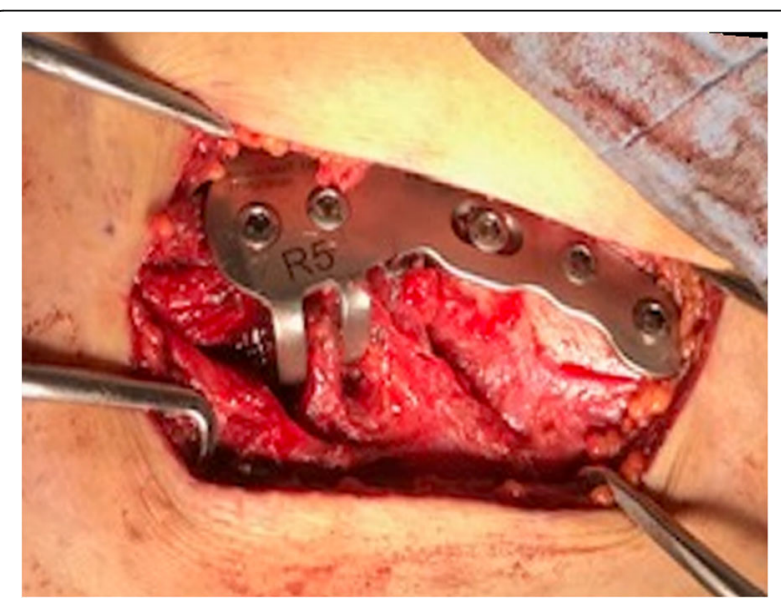

Fig. 4 Intraoperative image after osteosynthesis with the Scorpion plate. In the osteosynthesis using a SCORPION ${ }^{\circledR}$ NEO plate, two anteroposteriorly folded plate arms compressed and grasped the distal fragment. Two distal and three proximal cortical screws were then inserted to fix the plate 
Table 2 Comparison of incidence of postoperative complications and postoperative fracture gap (early group vs. delayed group)

\begin{tabular}{llll}
\hline & Early group $(n=45)$ & Delayed group $(n=60)$ & $P$ value \\
\hline Nonunion (one year after surgery) & $0(0 \%)$ & $6(10 \%)$ & $0.036^{*}$ \\
Plate loosening & $0(0 \%)$ & $4(6.7 \%)$ & 0.133 \\
Peri-implant fracture & $0(0 \%)$ & $0(0 \%)$ & - \\
Plate-related pain & $3(6.7 \%)$ & $4(6.7 \%)$ & 1 \\
Stiffness requiring arthroscopic capsulotomy & $0(0 \%)$ & $1(1.7 \%)$ & 1 \\
Postoperative fracture gap $(\mathrm{mm})$ & $0.9 \pm 1.7$ & $2.0 \pm 2.0$ & $0.004^{*}$ \\
\hline
\end{tabular}

${ }^{*} P<0.05$

SCORPION NEO ${ }^{\circ}$ plates, we compared the incidence of postoperative complications between the groups using $\mathrm{SCORPION}^{\circledast}$ plate and SCORPION NEO ${ }^{\circledR}$ plate.

\section{Statistical analysis}

All statistical analyses were conducted using SPSS version 26.0.0.0 (IBM, Armonk, NY). We used Student's $t$-tests to compare the average of continuous values (age, time from injury to surgery, and postoperative fracture gap) and chisquare tests to compare the proportion of discrete variables (sex, the side of injury, smoking, type of fracture, type of the plates, and additional fixation with Kirschner wire or suture anchor) between the early and delayed groups. When comparing the proportion of variables, especially if the expected value of the variable was less than five (nonunion, plate loosening, peri-implant fracture, plate-related pain, and stiffness requiring arthroscopic capsulotomy), Fischer's exact test was used. Continuous data are presented as mean \pm standard deviations (SD). The threshold for significance was $P<0.05$.

\section{Results}

In this study, although there was a significant difference in the time from injury to surgery between the early and delayed groups $(P<0.001)$, there were no significant differences in age, sex, affected side, smoking rate, type of clavicle fracture, type of plates and additional fixation with a Kirschner Wire or a suture-anchor (Table 1). In addition, 28 patients from the early group and 40 patients from the delayed group removed the implants, which showed no significant difference between the early and delayed groups.

Among the 105 patients, nonunion 1year after surgery and plate loosening were observed in six (5.7\%) and four patients $(3.8 \%)$, respectively. Nonunion was only observed in the delayed group, and the frequency of nonunion was significantly higher in the delayed group than that in the early group $(P=0.036)$. Plate loosening was also only observed in the delayed group, but no significant difference was observed in comparison with the early group. Periimplant fractures were not observed in either group. There was no significant difference in the frequency of platerelated pain at 6 months after surgery between the two groups. Postoperative shoulder stiffness was observed in one patient in the delayed group, which required arthroscopic capsulotomy 2years after surgery. In addition, the postoperative fracture gap was significantly greater in the delayed group; it was $0.9 \pm 1.7 \mathrm{~mm}$ in the early group and $2.0 \pm 2.0 \mathrm{~mm}$ in the delayed group $(P=0.004)$ (Table 2$)$.

Among the six patients with nonunion, only one patient experienced shoulder pain during elevation and a mild limitation of the range of motion, while other patients were asymptomatic. In addition, a loosening of the screw inserted into the distal bone fragment was observed on radiographic images in two patients (Fig. 5). All patients with nonunion at 1 year were observed nonoperatively and bone union was finally obtained within 1.5 years (Table 3 ).

Additionally, we compared the outcome between the groups using SCORPION ${ }^{\bullet}$ plate and using SCORPION $\mathrm{NEO}^{\circ}$ plate. The proportion of males and additional fixation with Kirschner wire or suture anchor in the

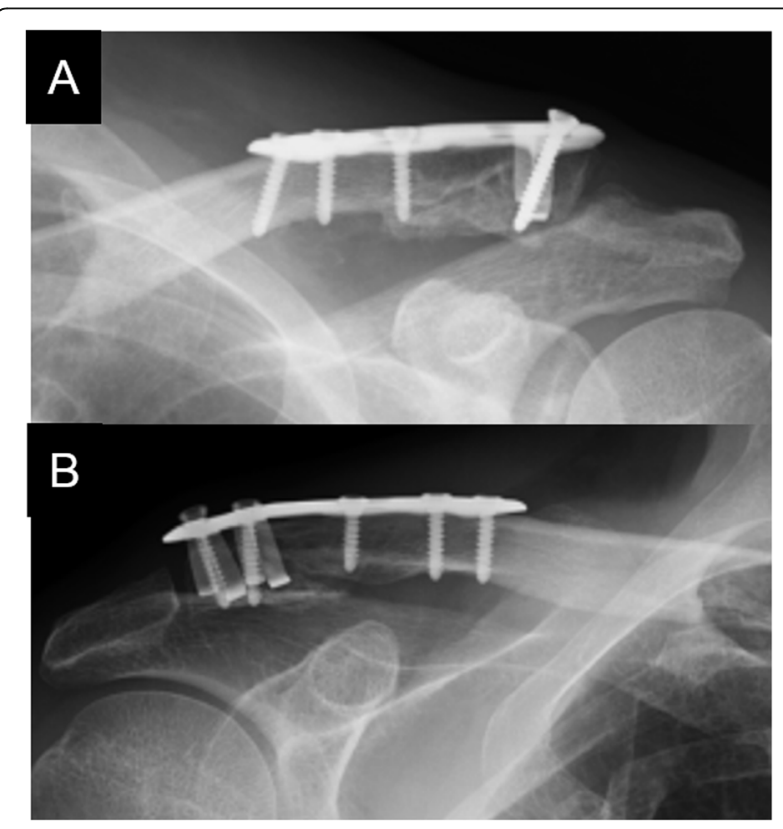

Fig. 5 Plain radiographs showing delayed bone union. Post-operative radiographs performed 1 year after surgery revealed that the fracture line is visible and the distal screws were loosening ( $\mathbf{a}$ and $\mathbf{b}$ ) 
Table 3 Details of patients experiencing delayed bone union. (0 females, 6 males, age range 24-72 years, median 38.5 years)

\begin{tabular}{llllll}
\hline & Age /Sex & Type (Neer) & Symptoms & Imaging findings & Clinical results \\
\hline Patient 1 & $32 /$ male & IIA & Asymptomatic & Residual postoperative fracture gap $(>3 \mathrm{~mm})$ & Bone union at 1.2 years \\
Patient 2 & $24 /$ male & IIB & Asymptomatic & - & Bone union at 1.3 years \\
Patient 3 & $34 /$ male & IIB & $\begin{array}{l}\text { Mild limitation in elevation }\left(135^{\circ}\right) \\
\text { Pain at elevation }\end{array}$ & Distal screw loosening & Bone union at 1.5 years \\
Patient 4 & $72 /$ male & $V$ & Asymptomatic & - & Bone union at 1.3 years \\
Patient 5 & $57 /$ male & IIB & Asymptomatic & Distal screw loosening & Bone union at 1.5 years \\
Patient 6 & $43 /$ male & $V$ & Asymptomatic & - & Bone union at 1.3 years \\
\hline
\end{tabular}

SCORPION NEO ${ }^{\circ}$ plate group was smaller than the proportion obtain in the SCORPION ${ }^{\bullet}$ plate group $(P<0.05)$; however, there were no significant differences in the time from injury to surgery, age, affected side, smoking rate, and type of clavicle fracture (Supplementary Table $1)$. There were also no significant differences in the incidence of postoperative complications between the SCORPION $^{\curvearrowleft}$ plate and SCORPION $\mathrm{NEO}^{\circ}$ plate groups, although the incidence of plate loosening tended to be lower in the group using SCORPION NEO ${ }^{\circ}$ plates $(0 \%$ vs $6.7 \%, P=0.133$ ) (Supplementary Table 2).

\section{Discussion}

In this study, we made two important clinical observations. First, results of this study indicated that osteosynthesis using Scorpion plates constitute a promising surgical treatment for unstable distal clavicle fractures. Second, this study suggested that delaying the surgical intervention for more than 6 days after injury is associated with the increased occurrence of nonunion 1 year after surgery in osteosynthesis using Scorpion plates for distal clavicle fractures.

First, our present results demonstrated that osteosynthesis using Scorpion plates for unstable distal clavicle fractures led to high bone union and low complication rates. In this study, six patients (5.7\%) experienced nonunion 1 year after surgery and one patient was symptomatic. However, bone union was ultimately achieved in all patients within 1.5 years after surgery. Previous studies investigating the clinical outcomes of at least 30 patients with distal clavicle fractures showed a bone union rate of $94-100 \%$ with hook plates $[10,12$, $14]$ and $97-100 \%$ with plates not fixed across the acromioclavicular joint $[13,14]$. Our findings suggest that the postoperative bone union rate observed with Scorpion plates can be equivalent to that of other plates. In distal clavicle fractures, distal fragments are fragile and often comminuted; therefore, stable fixation with screws is not always obtained. Scorpion plates can be used to fix distal fragments in a manner such that their arms wrap them with soft tissue en bloc. However, plate loosening was observed in four patients (3.8\%), presumably because Scorpion plates do not have locking screws. In all these patients, the loosening of screws inserted into distal bone fragments was observed, and the length of the distal screw was considered insufficient. These observations indicate that when performing fixation with the Scorpion plate, it is crucial to select the optimal distal screw length since distal bone fragments were fixed with only one or two screws in addition to the plate arm. Additionally, in this study, there were no reports of plate loosening in the SCORPION NEO ${ }^{\circ}$ group, whereas plate loosening was observed in four patients $(6.7 \%)$ in the SCORPION ${ }^{\circ}$ plate group. Although significant differences were not observed, there is the possibility that the number of plate arms might affect the bone fragment grasping force of the plates.

Second, this study demonstrated that the rate of nonunion was significantly higher when osteosynthesis using Scorpion plates was delayed for 7 days or more after injury. In addition, although the difference in frequency was not significant, plate loosening and stiffness were only seen in the delayed surgery group. These results suggest that delaying the surgical intervention for seven or more days after injury may be associated with an increase in postoperative complications of osteosyntheis using Scorpion plates for acute distal clavicle fractures. Regarding the timing of distal clavicle fracture surgery, the timing of surgery (less than 10 weeks after the injury vs. at least 10 weeks thereafter) reportedly did not affect clinical outcomes [23], while postoperative complications have been reported to increase in subjects that undergo surgery more than 4 weeks after injury $[16,20]$. However, the timing of surgery for acute fractures remains unclear. Recently, proximal humerus fracture fixation within 5 days of the fracture event was recommended, since a delayed intervention (six or more days after the injury) is related to a significant increase in complications [21], which is similar to the results of this study. A delayed surgical intervention is thought to complicate the anatomical fracture reduction and increase soft tissue dissection, which may result in a longer fracture union time [24]. In this study, the postoperative fracture gap is significantly greater in the delayed group, which supports the hypothesis that delayed surgical intervention makes the anatomical reduction difficult 
[24]; furthermore, it can explain our finding of a higher nonunion rate in the delayed surgery group compared with the early group. In this study, one patient who experienced nonunion 1 year after the operation was symptomatic (16.6\%), but reoperation was not required, and bone union was finally obtained 1.5 years after surgery. However, considering that some cases of nonunion or plate loosening associated with delayed union were reported to require reoperation with iliac bone grafting $[18,19]$, performing osteosynthesis using Scorpion plates for acute distal clavicle fractures within 6 days after the injury would be preferable.

The incidence of complications after plate fixation for distal clavicular fractures has been reported to be $22 \%$ in a large-scale systematic review [14]; therefore, based on a power analysis assuming a $20 \%$ rate of postoperative complications, approximately 400 patients in total would be required in this study to show a $50 \%$ difference in the risk of postoperative complications. Based on this, the study may include effects owing to the timing of surgery and type of plates that could not be detected ( $\beta$-error). However, the number of fractures were relatively large in this clinical study on more than 100 patients over 10 years in this study, while a majority of previous studies on the surgical outcomes for distal clavicle fractures had a sample size of 50 or less. This can be considered a major strength of this study. In addition, we used Scorpion plates for all unstable distal clavicle fractures and the surgical procedure was standardized during the period, suggesting that the generalization of clinical results using Scorpion plates is possible.

In contrast, there were several major limitations to this study. First, it is difficult to accurately evaluate the superiority or inferiority of Scorpion plate to other implants since this study was not a comparative study between different implants. Second, because of this study's observational design, biases from unobserved differences may have affected the results. For example, the procedures were performed by 14 surgeons; however, the influence of the abilities of the surgeons or the assistants were not evaluated. Although smoking was reported as a risk factor for nonunion of distal clavicle fractures [19], smoking status was adjusted between the early and delayed groups in this study. Third, the state of the acromioclavicular joint could be another possible limitation. Because the coracoclavicular ligament can be damaged with distal clavicle fracture, acromioclavicular joint separation might concur following osteosynthesis. However, we could not accurately evaluate the state of the acromioclavicular joint because most of our cases lacked the radiographs of the contralateral acromioclavicular joint. Finally, since questionnaire surveys were not administered in this study, it was not possible to determine additional objective functional outcomes.

\section{Conclusion}

This study provides new information on the clinical effectiveness of Scorpion plates in the treatment of distal clavicle fractures. Further, as osteosynthesis using Scorpion plates for acute unstable distal clavicle fractures, performing surgery within 6 days after injuries is recommended to reduce postoperative complications.

\section{Supplementary information}

Supplementary information accompanies this paper at https://doi.org/10. 1186/s12891-020-3169-9.

Additional file 1: Supplementary Table 1. Patient demographics (Osteosynthesis using SCORPION ${ }^{\circledR}$ vs. SCORPION NEO ${ }^{\oplus}$ ).

Additional file 2: Supplementary Table 2. Comparison of incidence of postoperative complications (Osteosynthesis using SCORPION ${ }^{\circledR}$ vs. SCORPION NEO ${ }^{\circledast}$ ).

Abbreviations

SD: Standard deviation

\section{Acknowledgements}

We thank Yasuhiro Kiyota and Akira Yoshiyama (National Hospital Organization Tokyo Medical Center) for their contribution to the collection and interpretation of data.

\section{Authors' contributions}

All authors contributed to the study conception and design. Material preparation, data collection and analysis were performed by RF, MT, TH, MI, and AK. The first draft of the manuscript was written by RF and MT. NM, YK, $\mathrm{HA}$, and HM contributed to previous versions of the manuscript. All authors read and approved the final manuscript.

\section{Funding}

The authors certify that they or their institutions did not receive any support (e.g. grants, funding, payment or other benefits) or a commitment or agreement to provide such benefits in connection with the research or preparation of this manuscript. We also received no funding for the design of the study; the collection, analysis, and interpretation of data and in writing the manuscript.

\section{Availability of data and materials}

Data that support the findings of this study are available from the corresponding author on reasonable request.

\section{Ethics approval and consent to participate}

This study was approved by the National Hospital Organization Tokyo Medical Center Independent Ethics Committee (No.R19-037), and opt-out consent was performed for each patient on our hospital's bulletin board and web site. Opt-out consent relies on implicit consent, where willingness to participate is tacit or presumed, and can be retracted by active objection.

Consent for publication

Not applicable.

\section{Competing interests}

The authors declare that they have no competing interests.

\section{Author details}

${ }^{1}$ Department of Orthopaedic Surgery, National Hospital Organization Tokyo Medical Center, 2-5-1, Higashigaoka, Meguro-ku, Tokyo 152-8902, Japan. ${ }^{2}$ Department of Orthopaedic Surgery, Keio University School of Medicine, Shinjuku-ku, Tokyo, Japan. 
Received: 30 September 2019 Accepted: 26 February 2020

Published online: 04 March 2020

\section{References}

1. Nordqvist A, Petersson C, Redlund-Johnell I. The natural course of lateral clavicle fracture. 15 (11-21) year follow-up of 110 cases. Acta Orthop Scand. 1993;64:87-91

2. Robinson CM, Court-Brown CM, McQueen MM, Wakefield AE. Estimating the risk of nonunion following nonoperative treatment of a clavicular fracture. J Bone Joint Surg Am. 2004;86:1359-65.

3. Rokito AS, Zuckerman JD, Shaari JM, Eisenberg DP, Cuomo F, Gallagher MA A comparison of nonoperative and operative treatment of type II distal clavicle fractures. Bull Hosp Jt Dis. 2002;61:32-9.

4. Neer CS. Fractures and dislocations of the shoulder. In: Rockwood Jr CA, Green DP, editors. Fractures in adults. Philadelphia: Lippincott; 1984. p. 7112.

5. Neer CS. Fractures of the distal third of the clavicle. Clin Orthop Relat Res. 1968:58:43-50

6. Banerjee R, Waterman B, Padalecki J, Robertson W. Management of distal clavicle fractures. J Am Acad Orthop Surg. 2011;19:392-401.

7. Sakai R, Matsuura T, Tanaka K, Uchida K, Nakao M, Mabuchi K. Comparison of internal fixations for distal clavicular fractures based on loading tests and finite element analyses. Sci World J. 2014;2014:817321. https://doi.org/10. $1155 / 2014 / 817321$

8. Fan J, Zhang Y, Huang Q, Jiang X, He L. Comparison of treatment of acute unstable distal clavicle fractures using anatomical locking plates with versus without additional suture anchor fixation. Med Sci Monit. 2017;23:5455-61.

9. Fleming MA, Dachs R, Maqungo S, du Plessis JP, Vrettos BC, Roche SJ. Angular stable fixation of displaced distal-third clavicle fractures with superior precontoured locking plates. J Shoulder Elb Surg. 2015;24:700-4.

10. Flinkkilä T, Ristiniemi J, Lakovaara M, Hyvönen P, Leppilahti J. Hook-plate fixation of unstable lateral clavicle fractures: a report on 63 patients. Acta Orthop. 2006:77:644-9.

11. Ibrahim S, Meleppuram JJ. Retrospective study of superior anterior plate as a treatment for unstable (Neer type 2) distal clavicle fractures. Rev Bras Ortop. 2017:53:306-13

12. Kashii M, Inui H, Yamamoto K. Surgical treatment of distal clavicle fractures using the clavicular hook plate. Clin Orthop Relat Res. 2006;447:158-64.

13. Martetschläger F, Kraus TM, Schiele CS, Sandmann G, Siebenlist S, Braun KF, Stöckle U, Freude T, Neumaier M. Treatment for unstable distal clavicle fractures (Neer 2) with locking T-plate and additional PDS cerclage. Knee Surg Sports Traumatol Arthrosc. 2013;21:1189-94.

14. Zhang C, Huang J, Luo Y, Sun H. Comparison of the efficacy of a distal clavicular locking plate versus a clavicular hook plate in the treatment of unstable distal clavicle fractures and a systematic literature review. Int Orthop. 2014:38:1461-8.

15. Lee W, Choi CH, Choi YR, Lim KH, Chun YM. Clavicle hook plate fixation for distal-third clavicle fracture (Neer type II): comparison of clinical and radiologic outcomes between Neer types IIA and IIB. J Shoulder Elb Surg. 2017:26:1210-5

16. Klein SM, Badman BL, Keating CJ, Devinney DS, Frankle MA, Mighell MA. Results of surgical treatment for unstable distal clavicular fractures. J Shoulder Elb Surg. 2010;19:1049-55.

17. Xiong J, Chen JH, Dang Y, Zhang DY, Fu ZG, Zhang PX. Treatment of unstable distal clavicle fractures (Neer type II): a comparison of three internal fixation methods. J Int Med Res. 2018;46:4678-83.

18. Brouwer KM, Wright TC, Ring DC. Failure of superior locking clavicle plate by axial pull-out of the lateral screws: a report of four cases. J Shoulder Elb Surg. 2009;18:e22-5.

19. Jarvis NE, Halliday L, Sinnott M, Mackenzie T, Funk L, Monga P. Surgery for the fractured clavicle: factors predicting nonunion. J Shoulder Elb Surg. 2018;27:e155-9.

20. Meda PV, Machani B, Sinopidis C, Braithwaite I, Brownson P, Frostick SP. Clavicular hook plate for lateral end fractures:- a prospective study. Injury. 2006;37:277-83.

21. Siebenbürger $G$, Van Delden D, Helfen T, Haasters F, Böcker W, Ockert B. Timing of surgery for open reduction and internal fixation of displaced proximal humeral fractures. Injury. 2015;46:S58-62.

22. Neer CS. Fracture of the distal clavicle with detachment of the coracoclavicular ligaments in adults. J Trauma. 1963;3:99-110.
23. Napora JK, Grimberg D, Childs BR, Vallier HA. Factors affecting functional outcomes after clavicle fracture. J Am Acad Orthop Surg. 2016;24:721-7.

24. Tang X, Liu L, Tu CQ, Li J, Li Q, Pei FX. Comparison of early and delayed open reduction and internal fixation for treating closed tibial pilon fractures. Foot Ankle Int. 2014;35:657-64.

\section{Publisher's Note}

Springer Nature remains neutral with regard to jurisdictional claims in published maps and institutional affiliations.
Ready to submit your research? Choose BMC and benefit from:

- fast, convenient online submission

- thorough peer review by experienced researchers in your field

- rapid publication on acceptance

- support for research data, including large and complex data types

- gold Open Access which fosters wider collaboration and increased citations

- maximum visibility for your research: over $100 \mathrm{M}$ website views per year

At BMC, research is always in progress.

Learn more biomedcentral.com/submissions 